\title{
Small but Critical Mistakes Commonly Made in Cell Culture Experiments: An Opinion Based on Observation and Experience
}

\author{
Sedat Kaçar* and Varol Şahintürk \\ Eskisehir Osmangazi University, Faculty of Medicine, Histology and Embryology Department, Turkey
}

Received: 㘹: September 14, 2018; Published: 制 September 20, 2018

*Corresponding author: Sedat Kaçar, Eskisehir Osmangazi University, Faculty of Medicine, Histology and Embryology Department, Turkey

Keywords: Cytotoxicity Assays; Stock Solution Preparation; Molar Volume

\section{Opinion}

Cell culture is indispensable for in vitro studies. Since in vivo experiments are carried out with organisms consisting of a whole cell, any invasive procedure is pre-determined, and the allowance of the ethical committee is applied, which delays your study. Sometimes quick experiments are needed to see the effect of a specific substance. In this case, cell culture assays allow us to quickly visualize the impact of a substance in vitro giving us the opportunity to utilize the target cell type in the body. However, there are some common mistakes made in cell culture. As is known, when a substance is tested in cell culture, the stock solution is first prepared. This solution is usually DMSO because of its ability to dissolve a wide range of substances. And the stock solution prepared should be at least 100 times the size of the dose to be given to the cells. This is a dilution method for reducing the toxic dose of DMSO. In spite of that of that non-toxic dose of DMSO is $0.1 \%, 100$-fold diluted DMSO is acceptable as long as untreated control with DMSO is also used.

However, when the stock solution is being prepared, the final volume is not considered. For example, assume that you will prepare $1 \mathrm{ml}$ and $100 \mathrm{mM}$ of stock solution from substance $\mathrm{X}$. The necessary amount of substance $\mathrm{X}$ is calculated for $1 \mathrm{ml}$ and transferred into the test tube, with which $1 \mathrm{ml}$ of solvent (usually DMSO) is often mixed. However, the molar volume of the substance $\mathrm{X}$ is not considered. The final volume of the solutions changes because of the molar volumes of the substances solubilized. Therefore, if we go from our example above, our stock solution to be prepared as $100 \mathrm{mM}$ is actually reduced to lower molarity due to molar volume effect. This causes us to miscalculate the doses we will use, changing the calculated IC50 and subsequent doses, leading to successive impacts. In addition, once wrongly prepared, stock solutions affect your follow-up experiments given that they are used for a long time by being stored at $-20^{\circ} \mathrm{C}$.
In this case, the best method is to adjust the final volume of solution to $1 \mathrm{ml}$ if we intend to prepare $1 \mathrm{ml}$ of the stock after the substance was put into the tube. Or if we know the molar volume of our substance to use in our experiment, we can determine how much volume it will increase in the final volume and put the solvent accordingly. A second issue is that in some cell culture cytotoxicity tests the blank, which only includes the medium is not used, and thus the cytotoxic effect is assessed only relative to the control group. Normally, cytotoxicity tests can be performed in 2 ways. It can be measured by subtracting the wavelength in which colored substance emits nearly no absorbance from the wavelength where the colored substance emits maximum absorbance or approximate wavelengths. Alternatively, only the absorbance values at the maximum wavelength where the substance emit are gained and analyzed. In this case, what happens when the blank is not used.

To exemplify, assume that the absorbance of the control is 0.6 , the absorbances of the other treated samples are $0.4,0.3$ and 0.2 , and the absorbance of the blank is 0.1. Assume that we assessed the viability rate in the samples without using blank. Examples 1, 2 and 3 correspond to the viability rates of $66.6 \%, 50 \%$, and $33.3 \%$, respectively. When the blank is subtracted from control in the calculation, the final absorbance values become 0.5 (control), 0.3 , 0.2 and 0.1 , and the viability percentages, in turn, become $100 \%$, $60 \%, 40 \%$, and $20 \%$, respectively. This makes a successive effect on our subsequent experiments by affecting the IC50, GI50 and other essential dose values used. So far we have shared the two most common errors we experienced in cell culture. I think that the elimination of these mistakes is very critical for more precise and accurate results. 
ISSN: 2574-1241

DOI: $10.26717 / B J S T R .2018 .09 .001762$

Sedat Kaçar. Biomed J Sci \& Tech Res

(c) (i) This work is licensed under Creative

Submission Link: https://biomedres.us/submit-manuscript.php

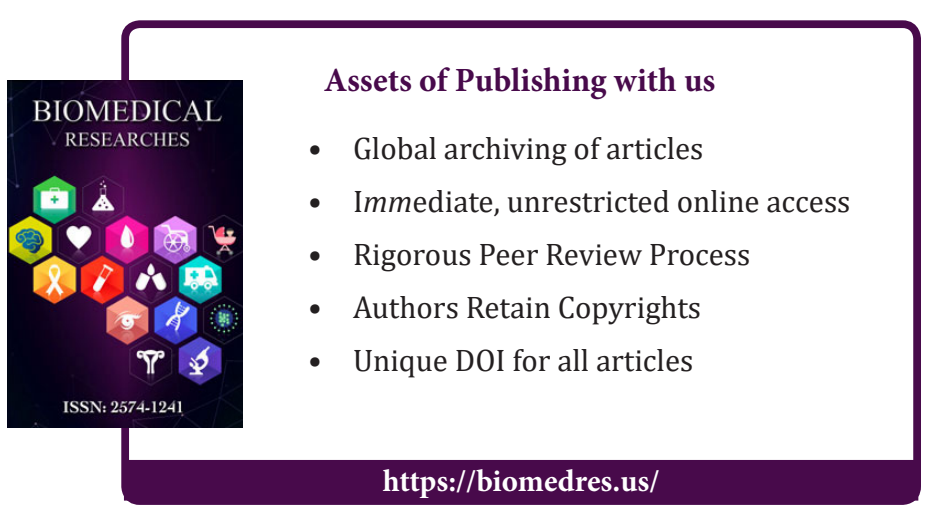

